\title{
Proceeding
}

9th INSHS International Christmas Sport Scientific Conference, 4-6 December 2014. International Network of Sport and Health

Science. Szombathely, Hungary

\section{The evaluation of the differences in energy expenditure of adults walking}

\author{
PAVLA KOURILOVA ,TOMAS KALINA, MARTINA BERNACIKOVA \\ Faculty of Sports Studies, Masaryk University, Brno, Czech Republic
}

\begin{abstract}
Kouriklova, P., Kalima, T., \& Bernacikova, M. (2015). The evaluation of the differences in energy expenditure of adults walking. J. Hum. Sport Exerc., 9(Proc1), pp.S404-S409. Introduction: This study describes differences between oxygen uptake $\left(\mathrm{VO}_{2} ; \mathrm{ml}^{\prime} \mathrm{min}^{-1} \cdot \mathrm{kg}^{-1}\right)$ and energy expenditure (EE; kJ.min$\left.{ }^{1} \cdot \mathrm{kg}^{-1}\right)$ during treadmill walking at various velocities $\left(3,4\right.$ and $\left.5 \mathrm{~km} \cdot \mathrm{h}^{-1}\right)$ and inclinations $(0,+12 \mathrm{a}-12 \%)$. Six men [age 22,83 $\pm 2,23$ y.0., weight (BM) 75,18 $\pm 4,83 \mathrm{~kg}$, height 180,5 $\pm 4,51 \mathrm{~cm}$; body fat (PBF) 15,3 \pm $3,67 \%$ of $\mathrm{BM}]$. Anthropometric variables and walking test were been performed during one session. Walking test consisted of 5 minutes stages (all combination of 3 velocities and 3 inclination, total test length of 45 minutes) and at the last two minutes of each stage were collected $\mathrm{EE}$ and $\mathrm{VO}_{2}$ in breath-by-breath analysis. Significant difference $(p<.05)$ were discovered between the velocities at same inclination in $\mathrm{VO}_{2}$ and EE except walking downhill at velocities of 3-4 $(p=.074)$ and $4-5 \mathrm{~km}(p=.116$, reps. $p=.106)$. The most noticeable change is the diversity of $\mathrm{VO}_{2}$ and $\mathrm{EE}$ between the various speeds at different treadmill inclinations. No significant relations were found between anthropometric variables and $\mathrm{VO}_{2}$, resp. EE, with the only exception BM vs. EE at $3 \mathrm{~km} \cdot \mathrm{h}^{-1}+12 \%(r=.84)$. Key words: GAIT, FAT, MEN, BREATH-BYBREATH, TREADMILL.
\end{abstract}

\footnotetext{
Corresponding author. Tomáš Kalina, Faculty of Sports Studies, Kamenice 753/5, 62500 Brno, Czech Republic E-mail: tkalina@fsps.muni.cz 9th INSHS International Christmas Sport Scientific Conference, 4-6 December 2014. International Network of Sport and Health Science. Szombathely, Hungary. JOURNAL OF HUMAN SPORT \& EXERCISE ISSN 1988-5202

(c) Faculty of Education. University of Alicante doi:10.14198/jhse.2015.10.Proc1.32
} 


\section{INTRODUCTION}

Walking is the most natural movement of human activity. Reduction of amount of physical activity (PA) is observed in recent decades in European countries (Hamrik, Sigmundová, Kalman, Pavelka, \& Sigmund, 2014; Bassett, Pucher, Buehler, Thompson, \& Crouter, 2008). This phenomenon is closely link with the epidemic of obesity and the risk of lifestyle diseases.

One component of the PA is walking, which can be understood not only as a type of transportation but also as a way of increasing energy expenditure during the day (Sedlacek, Sebera, Michalek, \& Cacek, 2013). Total energy consumption in performing walk is dependent on the duration, distance, intensity (speed and incline) (Waters, Lunsford, Perry, \& Byrd, 1988).

This study focuses on description of differences between oxygen uptake and energy expenditure during treadmill walking at various velocities and inclinations.

\section{MATERIAL AND METHODS}

\section{Participants}

The research was conducted in six selected males, non-athletes (not engaged in regular sporting activities), students of the Masaryk University. Participants' characteristics are shown in table 1. All students participated in the study voluntarily.

Table 1. Descriptive statistics of participants

\begin{tabular}{ccc}
\hline & Mean & SD \\
\hline Age & 22,83 & 2,23 \\
Weight $(\mathrm{kg})$ & 75,18 & 4,83 \\
Height $(\mathrm{kg})$ & 180,50 & 4,51 \\
Body fat (\% of body mass) & 15,31 & 3,67 \\
\hline
\end{tabular}

In order to ensure respect for the use of information and integrity of patients, all athletes were informed of the type of study, the tests and potential risks. The approval on the use of the data was certified by signature and fingerprint.

All procedures were approved by the ethics committee of the Santo Tomás University and conform to the principles outlined in the Declaration of Helsinki, in the same way the tests to be performed are considered minimal risk in accordance with Article 10 of resolution 8430 of 1993 which apply to Colombia.

The total number of participants who met the criteria and participated signed the consent and took part in the assessment was 17 males, mean age $18.2 \pm 1.8$ years, weight $62.8 \pm 7.4 \mathrm{~kg}$, height $170.1 \pm 5.8 \mathrm{~cm}$. The overall characteristics are in Table 1. 
Table 1. Physical characteristics of participants $n=17$

\begin{tabular}{ccc}
\hline & Average & SD \\
\hline Age $($ years $)$ & 18.2 & \pm 1.8 \\
Weight $(\mathrm{Kg})$ & 62.8 & \pm 7.4 \\
Height $(\mathrm{cm})$ & 170.1 & \pm 5.8 \\
Fat percentage & 10.0 & \pm 1.7 \\
Muscle percentage & 52.3 & \pm 4.4 \\
\hline
\end{tabular}

\section{Procedures}

The test protocol consisted of three inclination of the running/walking treadmill (Catana, Lode, The Netherlands). Each inclination parts included three subparts in itself. These three parts differed speed of movement $(3,4$ and $5 \mathrm{~km} / \mathrm{h})$. Completely nine subparts were performed in random order and with five minutes passive rest ( 5 minutes) after 3rd and 6th part. Each stage of test protocol lasted five minutes (total net time of walking test protocol: 45 minutes). During last two minutes of each stage, oxygen uptake (Metalyzer 3b, Cortex, Gemrnany), the breath-by-breath analysis, data were been collected. Body composition analysis were performed before test session (InBody 720, Biospace, Korea) according the manufacturer's recommendations. All participants underwent test protocol between $8 \mathrm{AM}$ and $11 \mathrm{AM}$.

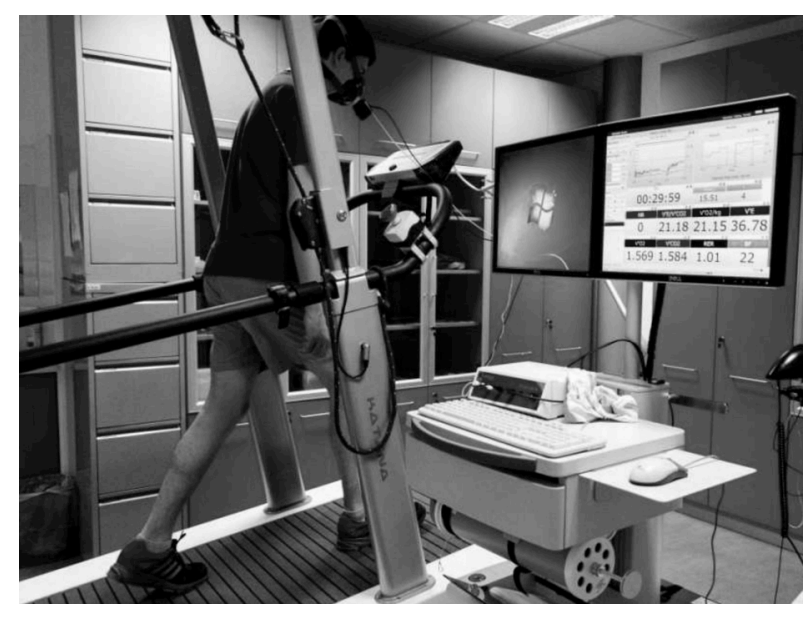

Figure 1. One of participants during test protocol ( $3 \mathrm{~km} / \mathrm{h}$ and $+12 \%$ inclination of treadmill)

The testing was conducted at a constant temperature of $20 \pm 1{ }^{\circ} \mathrm{C}$. Day before the testing session the tested subjects were asked to refrain from any sports and exhausting activities. Before each measurement, the calibration of Metalyzer 3b was performed by a calibration syringe (3 Liter Calibration Syringe, Cortex, Germany).

\section{Analysis}

The obtained data were expressed as oxygen uptake $\left(\mathrm{VO}_{2} ; \mathrm{ml}^{\prime} \mathrm{kg}^{-1} \cdot \mathrm{min}^{-1}\right)$ and energy expenditure (EE; $\mathrm{kJ} \cdot \mathrm{min}^{-1} \mathrm{~kg}^{-1}$ ) and changes velocities were observed by Wilcoxon signed-rank test. Spearman rank order correlation coefficient was used for analysis of relation selected anthropometric variables (weight, height and percent of body fat) with $\mathrm{EE}$ and $\mathrm{VO}_{2}$, respectively. The level of $p<0.05$ was considered as statistically significant. The software program Statistica 12 (StatSoft, USA) was used for all statistical analyses. 


\section{RESULTS}

Statistical significant difference $(p<.05)$ were discovered between the velocities at same inclination in $\mathrm{VO}_{2}$ and EE except walking downhill at velocities of $3 \mathrm{vs.} 4 \mathrm{~km} / \mathrm{h}(p=.074)$ and $4 \mathrm{vs.} 5 \mathrm{~km}\left(\mathrm{VO}_{2} p=.116\right.$ and $p$ $=.106 \mathrm{EE}$, resp.). The most noticeable variances are present at $\mathrm{VO}_{2}$ and $\mathrm{EE}$ among the various speeds during downhill (-12\% inclination) walking (see figure 2 and 3 and table 1 and 2 ).

Table 2. Results of oxygen uptake $\left(\mathrm{VO}_{2}\right)$ in different velocities and inclinations (result displayed as mean \pm SD $\mathrm{ml} \cdot \mathrm{kg}-1 \cdot \mathrm{min}-1)$

\begin{tabular}{llll}
\hline & $3 \mathrm{~km} \cdot \mathrm{h}-1$ & $4 \mathrm{~km} \cdot \mathrm{h}-1$ & $5 \mathrm{~km} \cdot \mathrm{h}-1$ \\
\hline$-12 \%$ & $9,65 \pm 1,53$ & $12,12 \pm 3,66$ & $12,68 \pm 3,1$ \\
$0 \%$ & $11,19 \pm 0,98$ & $12,13 \pm 0,8$ & $14,25 \pm 2,08$ \\
$+12 \%$ & $18,97 \pm 0,93$ & $22,81 \pm 1,14$ & $27,16 \pm 1,22$ \\
\hline
\end{tabular}

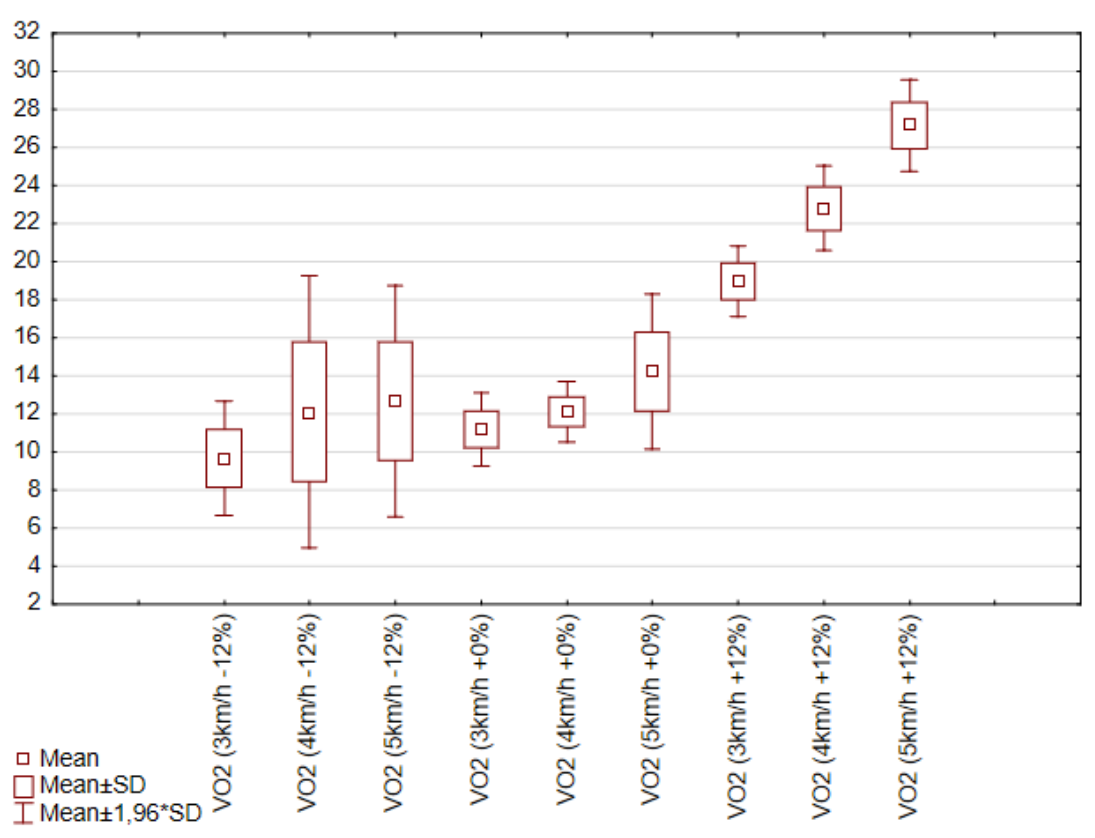

Figure 2. Results of oxygen uptake $\left(\mathrm{VO}_{2}\right)$ in different velocities and inclinations (result displayed in $\mathrm{ml} \cdot \mathrm{kg}^{-1} \cdot \mathrm{min}^{-1}$ )

Table 3. Results of energy expenditure $(\mathrm{EE})$ in different velocities and inclinations (result displayed as mean $\pm \mathrm{SD} \mathrm{kJ} \cdot \mathrm{min}^{-1} \cdot \mathrm{kg}^{-1}$ )

\begin{tabular}{cccc}
\hline & $3 \mathrm{~km} \cdot \mathrm{h}-1$ & $4 \mathrm{~km} \cdot \mathrm{h}-1$ & $5 \mathrm{~km} \cdot \mathrm{h}^{-1}$ \\
\hline & $0,1933 \pm$ & $0,245 \pm$ & $0,2567 \pm$ \\
$-12 \%$ & 0,0288 & 0,0706 & 0,0609 \\
\hline & $0,2233 \pm$ & $0,245 \pm$ \\
$0 \%$ & 0,0151 & 0,0138 & $0,29 \pm 0,0405$ \\
\hline & $0,3817 \pm$ & $0,4683 \pm$ \\
$+12 \%$ & 0,0147 & 0,0172 & $0,56 \pm 0,0228$ \\
\hline
\end{tabular}




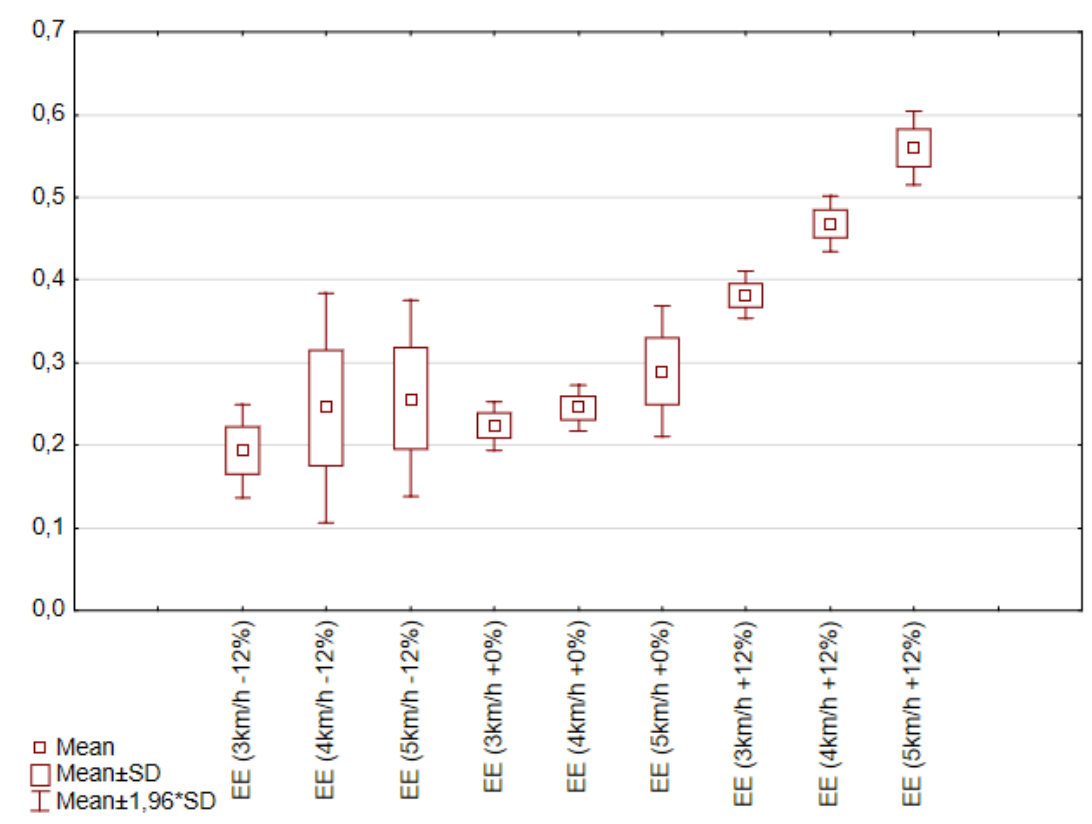

Figure 3. Results of energy expenditure (EE) in different velocities and inclinations (result displayed in $\mathrm{kJ} \cdot \mathrm{min}^{-1} \cdot \mathrm{kg}^{-1}$ )

No significant relations were found between anthropometric variables and $\mathrm{VO}_{2}$, resp. $\mathrm{EE}$, with the only exception BM vs. EE at $3 \mathrm{~km} \cdot \mathrm{h}^{-1}+12 \%(r=.84, p=.036)$.

\section{DISCUSSION AND CONCLUSION}

This study confirmed the expected differences between oxygen uptake $\left(\mathrm{VO}_{2}\right)$ and energy expenditure (EE) while walking on a treadmill at different speeds and inclinations. Noteworthy results of downhill walking, where there is a large variance in the results of a non-significant differences between similar speeds. This phenomenon can probably be attributed to differences in the time-spatial muscle involvement in the gait cycle. Furthermore, also confirmed the dependence between selected anthropometric characteristics and $\mathrm{VO}_{2}$ and EE, respectively.

\section{SOURCE OF FUNDING FOR THE STUDY}

This investigation was conducted within the framework of a specific students' research at the Masaryk University 0872/2013 "Walking economy of Czech younger adults population".

\section{REFERENCES}

1. Bassett Jr, D.R., Pucher, J., Buehler, R., Thompson, D.L., \& Crouter, S.E. (2008). Walking, cycling, and obesity rates in Europe, North America, and Australia. J Phys Act Health, 5(6), pp.795-814.

2. Bobbert, A.C. (1960). Energy expenditure in level and grade walking. J Appl Physiol, 15(6), pp.1015-1021.

3. Dean, G.A. (1965). An analysis of the energy expenditure in level and grade walking. Ergonomics, 8(1), pp.31-47. 
4. Hamrik, Z., Sigmundová, D., Kalman, M., Pavelka, J., \& Sigmund, E. (2014). Physical activity and sedentary behaviour in Czech adults: Results from the GPAQ study. Eur J Sport Sci, 14(2), pp.193-198.

5. Minetti, A.E., Moia, C., Roi, G.S., Susta, D., \& Ferretti, G. (2002). Energy cost of walking and running at extreme uphill and downhill slopes. J Appl Physiol, 93(3), pp.1039-1046.

6. Sedlacek, J., Sebera, M., Michalek, J., \& Cacek, J. (2013). Determination of socio-culturel characteristics on somatic parameter body mass index in Czech adult population. Journal Of Human Sport And Exercise, 8(2Proc), pp.30-35.

7. Waters, R.L., Lunsford, B.R., Perry, J., \& Byrd, R. (1988). Energy-speed relationship of walking: standard tables. J Orthopaed Res, 6(2), pp.215-222. 